\title{
Promoção do aleitamento materno: uma revisão integrativa das práticas educativas
}

\author{
Promotion of breastfeeding: an integrative review of educational practices \\ Promoción de la lactancia materna: una revisión integrativa de las prácticas educativas
}

Recebido: 21/09/2021 | Revisado: 26/09/2021 | Aceito: 27/09/2021 | Publicado: 28/09/2021

\author{
Suzana Merigo \\ ORCID: https://orcid.org/0000-0003-4394-7715 \\ Universidade Centro de Ensino Superior de Maringá, Brasil \\ E-mail: suzimerigo@gmail.com \\ Júlia Lajús Mendes Cella \\ ORCID: https://orcid.org/0000-0001-9690-9419 \\ Universidade Centro de Ensino Superior de Maringá, Brasil \\ E-mail: julialajus@ @otmail.com \\ Raquel Gusmão Oliveira \\ ORCID: https://orcid.org/0000-0002-9130-6800 \\ Universidade Centro de Ensino Superior de Maringá, Brasil \\ E-mail: raquel.oliveira@ unicesumar.edu.br \\ Célia Maria Gomes Labegalini \\ ORCID: https://orcid.org/0000-0001-9469-4872 \\ Universidade Estadual do Paraná, Brasil \\ E-mail: celia.labegalini@gmail.com
}

\begin{abstract}
Resumo
Objetivo: compreender como se dão as práticas educativas envolvidas com mulheres gestantes e puérperas em relação à amamentação. Método: trata-se de uma revisão integrativa, de caráter exploratório, que visa reunir e sintetizar informações e resultados de pesquisas a fim de responder a questão norteadora: quais as práticas educativas utilizadas pelos profissionais da saúde para orientar as mulheres quanto a amamentação. Resultados: em relação aos profissionais envolvidos na educação para o aleitamento materno, os artigos indicaram principalmente a equipe multidisciplinar, incluindo o médico, o enfermeiro, o técnico de enfermagem e os agentes comunitários de saúde; sobre a análise dos locais e momentos em que as mulheres são orientadas apontaram as consultas de pré-natal nas Unidades Básicas de Saúde (UBS) como momento e lugar escolhido para as orientações; e em relação as práticas educativas utilizadas, verifica-se uma variedade de práticas, onde os grupos de gestantes mostram-se a estratégia mais relevante. Conclusão: foi possível observar que as estratégias e ações realizadas pela equipe multidisciplinar desde o acompanhamento durante o pré-natal até o momento da maternidade e pós-parto são de extrema importância para o êxito da amamentação. É imprescindível também, a efetivação de ações educativas diversas, especialmente a formação de grupos de gestantes, presenciais ou online que promovam o AME, fortalecendo a rede de atenção mãe/bebê e minimizando o desmame precoce.
\end{abstract}

Palavras-chave: Aleitamento materno; Atenção primária; Assistência.

\begin{abstract}
Objective: to understand the educational practices involved with pregnant and postpartum women regarding breastfeeding. Method: This is an integrative review, of exploratory nature, which aims to gather and synthesize information and research results in order to answer the guiding question: what are the educational practices used by health professionals to guide women regarding breastfeeding. Results: regarding the professionals involved in breastfeeding education, the articles indicated mainly the multidisciplinary team, including the doctor, the nurse, the nursing technician, and the community health workers; regarding the analysis of the places and times when women are guided, the articles pointed out the prenatal consultations in the Basic Health Units (BHU) as the time and place chosen for the guidance; and regarding the educational practices used, a variety of practices is verified, where the groups for pregnant women show themselves to be the most relevant strategy. Conclusion: it was possible to observe that the strategies and actions carried out by the multidisciplinary team from the follow-up during prenatal care to the moment of maternity and postpartum are extremely important for the success of breastfeeding. It is also essential to carry out various educational activities, especially the formation of groups of pregnant women, in person or online, that promote EBF, strengthening the mother/baby care network and minimizing early weaning.
\end{abstract}

Keywords: Breastfeeding; Primary Health care; Assistance.

\section{Resumen}

Objetivo: comprender cómo sí desarrollan las prácticas educativas con las mujeres embarazadas y las mujeres en relación con el amamantamiento. Método: sí trata de una revisión integradora, de carácter exploratorio, que pretende 
reunir y sintetizar información y resultados de investigaciones con el fin de responder a la pregunta norteadora: cuáles son las prácticas educativas utilizadas por los profesionales de la salud para orientar a las mujeres en materia de amamantamiento. Resultados: en relación con los profesionales implicados en la educación para la salud materna, los artículos indican principalmente un equipo multidisciplinar, que incluye al médico, al enfermero, al técnico de enfermería y a los agentes comunitarios de salud; sobre el análisis de los lugares y momentos en los que las mujeres son orientadas, sí apuntan las consultas prenatales en las Unidades Básicas de Salud (UBS) como momento y lugar elegidos para las orientaciones; y en relación con las prácticas educativas utilizadas, sí verifica una variedad de prácticas, en las que los grupos de gestantes muestran la estrategia más relevante. Conclusión: sí pudo observar que las estrategias y acciones realizadas por el equipo multidisciplinar desde el acompañamiento durante el prenatal hasta el momento de la maternidad y el posparto son de extrema importancia para el éxito del amamantamiento. También es imprescindible la realización de acciones educativas diversas, especialmente la formación de grupos de gestores, presenciales u online, que promuevan el AME, fortaleciendo la red de atención a la madre/bebé y minimizando el desmame precoz.

Palabras clave: La lactancia materna; Atención primaria; Asistencia.

\section{Introdução}

O processo da amamentação propicia inúmeros benefícios tanto para a criança como para a mãe, além de promover a nutrição, atua na defesa contra infecções, estimula o desenvolvimento cognitivo e emocional, bem como a interação entre mãe e filho e auxilia na saúde física e mental da mulher. (Visitin et al., 2015).

A partir de 2002, a Organização Mundial da Saúde (OMS), por meio do desenvolvimento da Estratégia Global para Alimentação de Lactentes e Crianças de Primeira Infância, recomenda o aleitamento materno exclusivo (AME) até os seis meses de vida, pois o leite materno é o alimento mais nutritivo para a criança, sendo rico em proteínas, carboidratos, sais mineiras, vitaminas e água; e após esta idade, estimula a alimentação complementar (AC) em conjunto com o aleitamento até dois anos ou mais. (Ramos et al., 2018).

Embora exista tal recomendação, as taxas de aleitamento materno exclusivo no Brasil ainda estão abaixo do esperado preconizado pela OMS, atingindo uma prevalência em crianças menores de seis meses de 41\%, com duração média de AME de 54,1 dias (menos de 2 meses). (Silva et al., 2014).

Segundo o Ministério da Saúde (2009), quanto ao AME em menores de seis meses, a situação é considerada ruim, variando de $12 \%$ a $49 \%$ a prevalência nas capitais brasileiras. A meta é aumentar para 50\%, classificado pela OMS como “bom”, até 2025 em todo país. No tocante à duração do aleitamento materno, o país se encontra em situação "muito ruim”, estando entre zero e 17 meses.

Destaca-se ainda que, além de motivos tangíveis fisiológicos e/ou questões anatômicas dos mamilos ou dos bebês, pressupõem-se que o desmame precoce é decorrente também do desconhecimento das mães sobre as vantagens do aleitamento exclusivo, das crendices populares sobre o leite materno, da falta de conhecimento e despreparo dos profissionais da saúde sobre como orientar corretamente as lactantes, da falta de apoio familiar e das políticas públicas deficientes na promoção do aleitamento materno. (Aleixo et al., 2019).

Portanto, estudos demonstram que receber orientação adequada sobre o aleitamento materno exclusivo contribui diretamente na atitude das mulheres frente ao ato de amamentar. Deste modo, os profissionais da saúde contribuem com o conhecimento técnico e por meio da escuta ativa, aconselham, realizam o acolhimento e sanam as dúvidas, atuando como atores de política pública na AME. (Brasil, 2015).

Dessa forma, conhecer os aspetos que envolvem as orientações sobre aleitamento materno ofertadas às mulheres brasileiras pelos profissionais de saúde pode auxiliar na compreensão das lacunas educativas e dos fatores de sucesso, contribuindo para elaboração de ações efetivas para a promoção da amamentação. Assim, o presente estudo objetivou responder: como se dão práticas educativas desenvolvidas com as mulheres gestantes e puérperas em relação à amamentação? 


\section{Metodologia}

Trata-se de uma revisão integrativa, de caráter exploratório, que almeja reunir e sintetizar informações e resultados de pesquisas a fim de responder a questão norteadora: Quais as práticas educativas utilizadas pelos profissionais da saúde para orientar as mulheres quanto a amamentação.

Na primeira etapa, definiu-se o tema da pesquisa: práticas educativas sobre amamentação; e realizou-se a seleção de hipóteses objetivando definir de maneira clara e específica a questão norteadora, supracitada. Na segunda etapa, estabeleceu-se os critérios para amostragem e busca nas bases de dados, incluindo as palavras-chaves utilizadas, os critérios de inclusão e os de exclusão dos estudos que passarão por seleção. (Souza et al., 2007).

Dessa forma, determinou-se que seriam utilizados e analisados artigos com as palavras-chaves: "amamentação", “aleitamento materno", "atenção primária à saúde" e "orientação" encontrados nos recursos de pesquisa sítios da Internet: Scientific Eletronic Library Online (SCIELO), Literatura Latino-Americana e do Caribe em Ciências da Saúde (LILACS), Ministério da Saúde e revistas da saúde (de âmbito estadual e nacional), entre os períodos de 2014 à 2021, posteriores à Portaria ${ }^{\circ} 1.153$ que incluiu critérios Cuidado Amigo da Mulher na Iniciativa Hospital Amigo da Criança.

A coleta de dados e seleção definitiva dos artigos ocorreu entre os meses de abril e junho de 2021, por meio das etapas: seleção dos artigos com a utilização das palavras chave já citadas anteriormente, evitando assim, trabalhos que não sejam pertinentes a esse estudo; realização da leitura dos resumos para certificação da relevância do tema exposto nos artigos, revistas e cartilhas; leitura destes materiais para a sistematização dos resultados apontados por eles.

Os critérios de inclusão foram: artigos relacionados à amamentação e sobre o auxílio do profissional nessa fase, disponibilidade online na íntegra; cartilhas da Organização Mundial da Saúde e Ministério da Saúde com as publicações mais atuais; artigos em inglês. Os critérios de exclusão definidos foram: não abordagem do tema pesquisado, estudos repetidos e artigos publicados em espanhol, pelo título, pelo resumo e pela leitura do texto na íntegra.

Após a pré-análise do total de 86 publicações obtidas, foram excluídas 65 trabalhos, sendo 15 por não terem os textos na íntegra disponíveis online, 34 excluídos após leitura dos títulos, 13 excluídos após leitura dos resumos e 3 excluídos após a leitura do artigo na íntegra, conforme demostrado no Quadro 1.

Quadro 1 - Seleção após aplicação dos critérios de inclusão e exclusão.

\begin{tabular}{|c|c|c|c|c|c|}
\hline $\begin{array}{c}\text { BASE DE } \\
\text { DADOS }\end{array}$ & ENCONTRADOS & $\begin{array}{c}\text { DISPONÍVEIS } \\
\text { ONLINE }\end{array}$ & $\begin{array}{c}\text { SELECIONADOS } \\
\text { POR TÍTULO }\end{array}$ & $\begin{array}{c}\text { SELECIONADOS } \\
\text { POR RESUMO }\end{array}$ & $\begin{array}{c}\text { ARTIGOS } \\
\text { ANALISADOS }\end{array}$ \\
\hline SCIELO & 13 & 12 & 8 & 2 & 13 \\
\hline LILACS & 21 & 15 & 6 & 3 & 12 \\
\hline $\begin{array}{c}\text { Google } \\
\text { Acadêmico }\end{array}$ & 33 & 25 & 6 & 3 \\
\hline $\begin{array}{c}\text { Ministério da } \\
\text { Saúde e OMS }\end{array}$ & 19 & 19 & & 24 & 21 \\
\hline TOTAL & 86 & 71 & 37 & & \\
\hline
\end{tabular}

Fonte: Autores (2021).

Os artigos que foram selecionados de acordo com os critérios de inclusão definidos foram organizados em um quadro sinóptico (Quadro 2), de acordo com Paiva et al. (2010), contemplando os seguintes itens: título do artigo, nome dos autores/ano de publicação, local/ instituição sede do estudo, base de dados/periódico, características metodológicas e amostra. 
Os estudos foram ordenados por ano de publicação e nomeados com a letra A (artigos) ou C (cartilha) e sequenciados em ordem numérica, por questão de organização.

Quadro 2 - Categorização dos artigos ordenada por ano de publicação.

\begin{tabular}{|c|c|c|c|c|c|}
\hline TÍTULO DO ARTIGO & $\begin{array}{c}\text { AUTORES/ } \\
\text { ANO }\end{array}$ & $\begin{array}{l}\text { LOCAL DO } \\
\text { ESTUDO }\end{array}$ & $\begin{array}{l}\text { BASE DE } \\
\text { DADOS }\end{array}$ & METODOLOGIA & AMOSTRA \\
\hline $\begin{array}{l}\text { A1. Estratégias e ações do } \\
\text { enfermeiro no incentivo ao } \\
\text { aleitamento materno: revisão } \\
\text { integrativa }\end{array}$ & $\begin{array}{l}\text { Viana MDZ, } \\
\text { Donaduzzi DSS, } \\
\text { Rosa AB, et al, } \\
2021 \\
\end{array}$ & $\begin{array}{l}\text { Rio de Janeiro, } \\
\text { UFRJ }\end{array}$ & $\begin{array}{l}\text { LILACS, Rev. de } \\
\text { Pesquisa Cuidado } \\
\text { é Fundamental } \\
\text { Online }\end{array}$ & Revisão integrativa & 14 publicações \\
\hline $\begin{array}{l}\text { A2.Amamentação na atenção } \\
\text { básica: as mães realizam essa } \\
\text { prática? }\end{array}$ & $\begin{array}{l}\text { Silva MS, Santos } \\
\text { PS, Silva VG, } \\
\text { Ribeiro PM, } 2021\end{array}$ & $\begin{array}{l}\text { Rio de Janeiro, } \\
\text { Unirio }\end{array}$ & $\begin{array}{l}\text { Rev. de Pesquisa } \\
\text { Cuidado é } \\
\text { Fundamental } \\
\text { Online }\end{array}$ & $\begin{array}{l}\text { Estudo transversal, } \\
\text { com abordagem } \\
\text { quantitativa de } \\
\text { natureza descritiva e } \\
\text { retrospectivo } \\
\end{array}$ & 120 nutrizes \\
\hline $\begin{array}{l}\text { A3.Percepções dos } \\
\text { profissionais de saúde acerca } \\
\text { dos fatores } \\
\text { biopsicossocioculturais } \\
\text { relacionados com o } \\
\text { aleitamento materno } \\
\end{array}$ & $\begin{array}{l}\text { Peres JF, } \\
\text { Carvalho ARS, } \\
\text { Viera CS, } \\
\text { Christoffel MM, } \\
\text { Toso BRGO, } \\
2021 \\
\end{array}$ & $\begin{array}{l}\text { Paraná, } \\
\text { Unioeste }\end{array}$ & $\begin{array}{l}\text { Scielo, Saúde em } \\
\text { Debate }\end{array}$ & $\begin{array}{l}\text { Estudo qualitativo, } \\
\text { descritivo e } \\
\text { exploratório }\end{array}$ & $\begin{array}{l}28 \text { profissionais } \\
\text { da saúde }\end{array}$ \\
\hline $\begin{array}{l}\text { A4.A importância do } \\
\text { aleitamento materno nos } \\
\text { primeiros anos de vida: uma } \\
\text { revisão bibliográfica }\end{array}$ & $\begin{array}{l}\text { KEPPLER, K. A. } \\
\text { et al, } 2020\end{array}$ & $\begin{array}{l}\text { Santos-SP, } \\
\text { UNIMES }\end{array}$ & Revista Higei@ & Revisão Bibliográfica & 10 artigos \\
\hline $\begin{array}{l}\text { A5.Análise do conhecimento } \\
\text { de pacientes e profissionais } \\
\text { de saúde de uma unidade de } \\
\text { saúde da família de porto } \\
\text { Velho -Rondônia-acerca do } \\
\text { aleitamento materno }\end{array}$ & $\begin{array}{l}\text { SILVA, A. C. R. } \\
\text { et al, } 2020\end{array}$ & $\begin{array}{l}\text { Porto Velho- } \\
\text { RO, UniSL }\end{array}$ & $\begin{array}{l}\text { Rev. Saber } \\
\text { científico }\end{array}$ & $\begin{array}{l}\text { Estudo exploratório, } \\
\text { transversal, descritivo } \\
\text { de abordagem } \\
\text { quantitativa. }\end{array}$ & $\begin{array}{l}47 \text { mulheres } \\
\text { gestantes ou } \\
\text { com lactentes } \\
\text { até os seis } \\
\text { meses de idade }\end{array}$ \\
\hline $\begin{array}{l}\text { A6.Conhecimentos das } \\
\text { gestantes acerca da } \\
\text { importância da Amamentação }\end{array}$ & $\begin{array}{l}\text { SILVA, S.M. et } \\
\text { al, } 2020\end{array}$ & $\begin{array}{l}\text { Teresina-PI, } \\
\text { Universidade } \\
\text { Estadual do } \\
\text { Piauí }\end{array}$ & $\begin{array}{l}\text { V Simpósio } \\
\text { Multiprofissional } \\
\text { em Cuidados } \\
\text { Materno-infantis } \\
2020 \\
\end{array}$ & Revisão bibliográfica & 11 artigos \\
\hline $\begin{array}{l}\text { A7.Fortalecedores e } \\
\text { fragilizadores da } \\
\text { amamentação na ótica da } \\
\text { nutriz e de sua família. }\end{array}$ & $\begin{array}{l}\text { WAGNER, L. P. } \\
\mathrm{B} \text { et al, } 2020\end{array}$ & $\begin{array}{l}\text { Curitiba-PR, } \\
\text { USP }\end{array}$ & $\begin{array}{l}\text { Scielo, } \\
\text { Rev. Esc. Enferm. }\end{array}$ & $\begin{array}{l}\text { Abordagem } \\
\text { qualitativa do tipo } \\
\text { estudo de casos } \\
\text { múltiplos com caráter } \\
\text { descritivo }\end{array}$ & $\begin{array}{l}\text { Membros de } \\
\text { famílias de } \\
\text { crianças de } 6 \text { a } \\
12 \text { meses }\end{array}$ \\
\hline $\begin{array}{l}\text { A8.Orientação da } \\
\text { amamentação na alta } \\
\text { hospitalar: uma revisão } \\
\text { integrativa }\end{array}$ & $\begin{array}{l}\text { MUCHA, A. M.; } \\
\text { LOHMANN, P. } \\
\text { M.; LASTE, G.; } \\
\text { MARCHESE, C., } \\
2020\end{array}$ & $\begin{array}{l}\text { Lajeado-RS, } \\
\text { Univates }\end{array}$ & $\begin{array}{l}\text { Research, Society } \\
\text { and Development }\end{array}$ & $\begin{array}{l}\text { Pesquisa descritiva, } \\
\text { de revisão de } \\
\text { literatura, do tipo } \\
\text { integrativa. }\end{array}$ & Literatura \\
\hline $\begin{array}{l}\text { A9.Atuação do enfermeiro da } \\
\text { estratégia saúde da família no } \\
\text { incentivo ao aleitamento } \\
\text { materno durante o período } \\
\text { pré-natal }\end{array}$ & $\begin{array}{l}\text { NASCIMENTO, } \\
\text { A. M. R. et al, } \\
2019\end{array}$ & $\begin{array}{l}\text { Minas Gerais, } \\
\text { Uniptan }\end{array}$ & $\begin{array}{l}\text { Revista Eletrônica } \\
\text { Acervo Saúde }\end{array}$ & Revisão narrativa & 30 artigos \\
\hline $\begin{array}{l}\text { A10.Promoção do } \\
\text { aleitamento materno: práticas } \\
\text { de médicos e enfermeiros da } \\
\text { atenção Primária à Saúde }\end{array}$ & $\begin{array}{l}\text { SILVA, R. M. M. } \\
\text { et al, } 2019\end{array}$ & Paraná, UFSJ & $\begin{array}{l}\text { Revista de } \\
\text { Enfermagem do } \\
\text { Centro-Oeste } \\
\text { Mineiro }\end{array}$ & Pesquisa qualitativa & $\begin{array}{l}35 \text { médicos e } 27 \\
\text { enfermeiros } \\
\text { atuantes no } \\
\text { serviço de } \\
\text { atenção } \\
\text { primária }\end{array}$ \\
\hline $\begin{array}{l}\text { A11.Conhecimento e análise } \\
\text { do processo de orientação de } \\
\text { puérperas acerca da } \\
\text { amamentação }\end{array}$ & $\begin{array}{l}\text { ALEIXO, } \\
\text { Thuanne Cristina } \\
\text { Sousa et al, } 2019\end{array}$ & $\begin{array}{l}\text { Minas Gerais, } \\
\text { Hospital de } \\
\text { Ensino de } \\
\text { Minas Gerais }\end{array}$ & $\begin{array}{l}\text { Rev. Enferm. } \\
\text { UFSM. }\end{array}$ & $\begin{array}{l}\text { Estudo descritivo } \\
\text { transversal }\end{array}$ & 69 puérperas \\
\hline $\begin{array}{l}\text { A12.Aleitamento materno: } \\
\text { orientações recebidas por } \\
\text { gestantes acompanhadas pela }\end{array}$ & $\begin{array}{l}\text { FERREIRA, } \\
\text { MGC., GOMES, } \\
\text { MFP., }\end{array}$ & São Paulo, USP & Rev. Aten. Saúde & $\begin{array}{l}\text { Pesquisa descritiva e } \\
\text { exploratória }\end{array}$ & 24 gestantes \\
\hline
\end{tabular}




\begin{tabular}{|c|c|c|c|c|c|}
\hline estratégia saúde da família & $\begin{array}{l}\text { FRACOLLI, LA., } \\
2018\end{array}$ & & & & \\
\hline $\begin{array}{l}\text { A13.Desmame precoce em } \\
\text { crianças atendidas na } \\
\text { Estratégia Saúde da Família }\end{array}$ & $\begin{array}{l}\text { Santos PV, } \\
\text { Martins MCC, } \\
\text { Tapety FI, Paiva } \\
\text { AA, Fonseca } \\
\text { FMNS, Brito } \\
\text { AKS., 2018 } \\
\end{array}$ & $\begin{array}{l}\text { Teresina-PI, } \\
\text { Centro } \\
\text { Universitário } \\
\text { UNINOVAFAP } \\
\text { I }\end{array}$ & Rev. Eletr. Enf. & $\begin{array}{l}\text { Pesquisa quantitativa, } \\
\text { descritiva e } \\
\text { exploratória }\end{array}$ & 241 crianças \\
\hline $\begin{array}{l}\text { A14.Facilidades e } \\
\text { dificuldades encontradas } \\
\text { pelas puérperas para } \\
\text { amamentar }\end{array}$ & $\begin{array}{l}\text { Urbanetto PDG; } \\
\text { Gomes GC; Costa } \\
\text { AR; et al, } 2018\end{array}$ & $\begin{array}{l}\text { Rio Grande do } \\
\text { Sul, FURG }\end{array}$ & $\begin{array}{l}\text { Rev. Fund Care } \\
\text { Online }\end{array}$ & $\begin{array}{l}\text { Estudo descritivo } \\
\text { exploratório de cunho } \\
\text { qualitativo }\end{array}$ & $\begin{array}{l}11 \text { puérperas em } \\
\text { um Hospital } \\
\text { Universitário do } \\
\text { sul do Brasil }\end{array}$ \\
\hline $\begin{array}{l}\text { A15.Orientações sobre } \\
\text { amamentação na atenção } \\
\text { básica de saúde e associação } \\
\text { com o aleitamento materno } \\
\text { exclusivo. }\end{array}$ & $\begin{array}{l}\text { ALVES, J. S.; } \\
\text { OLIVEIRA, M. I. } \\
\text { C.; RITO, R., } \\
2018\end{array}$ & $\begin{array}{l}\text { Rio de Janeiro, } \\
\text { UFF }\end{array}$ & $\begin{array}{l}\text { Scielo; } \\
\text { Ciência e Saúde } \\
\text { Coletiva }\end{array}$ & Estudo transversal & $\begin{array}{l}429 \text { mães de } \\
\text { crianças } \\
\text { menores de seis } \\
\text { meses }\end{array}$ \\
\hline $\begin{array}{l}\text { C16.Protecting, promoting } \\
\text { and supporting } \\
\text { Breastfeeding in facilities } \\
\text { providing } \\
\text { Maternity and newborn } \\
\text { services: the revised } \\
\text { Baby-friendly } \\
\text { Hospital initiative }\end{array}$ & $\begin{array}{l}\text { World Health } \\
\text { Organization and } \\
\text { the United } \\
\text { Nations } \\
\text { Children's Fund } \\
\text { (UNICEF), } 2018\end{array}$ & Geneva & $\begin{array}{l}\text { World Health } \\
\text { Organization }\end{array}$ & $\begin{array}{l}\text { Orientação de } \\
\text { implementação }\end{array}$ & Sem informação \\
\hline $\begin{array}{l}\text { A17.Conhecimento sobre } \\
\text { aleitamento materno e } \\
\text { alimentação complementar } \\
\text { dos profissionais de saúde. }\end{array}$ & $\begin{array}{l}\text { Ramos AE, } \\
\text { Ramos CV, } \\
\text { Santos MM, } \\
\text { Almeida CAPL, } \\
\text { Martins MCC., } \\
2018\end{array}$ & $\begin{array}{l}\text { Teresina-PI, } \\
\text { Centro } \\
\text { Universitário } \\
\text { UNINOVAFAP } \\
\text { I }\end{array}$ & $\begin{array}{l}\text { Scielo; } \\
\text { Rev. Brasileira de } \\
\text { Enfermagem }\end{array}$ & Estudo transversal & $\begin{array}{l}168 \\
\text { profissionais da } \\
\text { saúde }\end{array}$ \\
\hline $\begin{array}{l}\text { A18.Avaliação do } \\
\text { conhecimento de puérperas } \\
\text { acerca da amamentação. }\end{array}$ & $\begin{array}{l}\text { VISITIN, Alice } \\
\text { Brito et al, } 2015\end{array}$ & $\begin{array}{l}\text { São Mateus-ES, } \\
\text { UFES }\end{array}$ & $\begin{array}{l}\text { Rev. Enfermagem } \\
\text { em Foco }\end{array}$ & Pesquisa Descritiva & 323 puérperas \\
\hline $\begin{array}{l}\text { C19.Estratégia nacional para } \\
\text { promoção do aleitamento } \\
\text { materno e alimentação } \\
\text { complementar saudável no } \\
\text { Sistema Único de Saúde. }\end{array}$ & $\begin{array}{l}\text { Ministério da } \\
\text { Saúde, } 2015\end{array}$ & Brasília-DF & $\begin{array}{l}\text { Cartilha } \\
\text { Ministério da } \\
\text { Saúde }\end{array}$ & $\begin{array}{l}\text { Manual de } \\
\text { implementação com } \\
\text { referencial teórico }\end{array}$ & $\begin{array}{l}\text { Referencial } \\
\text { teórico }\end{array}$ \\
\hline $\begin{array}{l}\text { C20.Saúde da Criança: } \\
\text { Aleitamento Materno e } \\
\text { Alimentação Complementar. }\end{array}$ & $\begin{array}{l}\text { Ministério da } \\
\text { Saúde, } 2015\end{array}$ & Brasília-DF & $\begin{array}{l}\text { Cartilha } \\
\text { Ministério da } \\
\text { Saaúde } \\
\end{array}$ & $\begin{array}{l}\text { Caderno de atenção } \\
\text { básica }\end{array}$ & $\begin{array}{l}\text { Referencial } \\
\text { teórico }\end{array}$ \\
\hline $\begin{array}{l}\text { A21.Conhecimento de } \\
\text { puérperas sobre amamentação } \\
\text { exclusiva }\end{array}$ & $\begin{array}{l}\text { SILVA, Nichelle } \\
\text { Monique et al, } \\
2014\end{array}$ & $\begin{array}{l}\text { Caxias do Sul- } \\
\text { RS, UFCSPA }\end{array}$ & $\begin{array}{l}\text { Scielo; } \\
\text { Rev. Bras. } \\
\text { Enferm. }\end{array}$ & $\begin{array}{l}\text { Estudo descritivo com } \\
\text { abordagem qualitativa }\end{array}$ & 13 puérperas \\
\hline
\end{tabular}

Fonte: Autores (2021).

A terceira etapa consistiu em categorizar os artigos selecionados e definir as informações e ideias a serem extraídas, criando um banco de dados organizado e sumarizado (Quadro 3) abrangendo todas as informações pertinentes de cada estudo. A categorização foi feita a fim de atender o objetivo do estudo, identificando: "profissionais envolvidos nas orientações às mulheres quanto a amamentação", "práticas educativas utilizadas" e "momentos e locais para orientação das mulheres".

Na quarta etapa, houve a análise detalhada e crítica dos artigos, buscando explicações para possíveis variações ou resultados conflitantes entre diferentes estudos. Após essa avaliação, na quinta etapa, foi feita a discussão e interpretação dos resultados, comparando com conhecimentos teóricos e identificando lacunas que surgiram. Por fim, como sexta e última etapa, haverá a apresentação da pesquisa, comtemplando todas as etapas percorridas, e a síntese do conhecimento com divulgação dos resultados obtidos. (Souza et al., 2007). 


\section{Resultados}

Das publicações analisadas, doze (57\%) foram localizadas no Google Acadêmico, cinco (24\%) constava na SCIELO, uma (5\%) na LILACS, e três cartilhas do Ministério da Saúde (14\%). Foi constatado que o ano que apresentou maior número de publicações foi 2018, com seis (28\%) estudos. Os artigos foram produzidos majoritariamente no Brasil (95\%), sendo apenas um na Suíça (5\%).

As publicações selecionadas nesta revisão são originadas de 15 tipos diferentes de revistas, sendo os periódicos com mais publicações a Revista de Pesquisa Cuidado é Fundamental Online e a Revista Brasileira de Enfermagem, ambas com dois (9\%) artigos cada. De acordo com as características metodológicas dos estudos, 5 (24\%) artigos são revisões de narrativa, 13 (62\%) são estudos transversais e 3 (14\%) são cartilhas do Ministério da Saúde.

Quadro 3 - Distribuição dos estudos quanto aos profissionais e locais de orientação.

\begin{tabular}{|c|c|c|c|}
\hline $\begin{array}{l}\text { ARTI } \\
\text { GO }\end{array}$ & $\begin{array}{l}\text { PROFISSIONAIS } \\
\text { ENVOLVIDOS NA } \\
\text { ORIENTAÇÃO } \\
\end{array}$ & $\begin{array}{l}\text { PRATICAS EDUCATIVAS } \\
\text { UTILIZADAS }\end{array}$ & $\begin{array}{c}\text { MOMENTOS E LUGARES EM QUE AS } \\
\text { MULHERES ESTÃO SENDO } \\
\text { ORIENTADAS }\end{array}$ \\
\hline 1 & Enfermeiro. & $\begin{array}{l}\text { Oficinas, palestras educativas, vídeos, } \\
\text { atividades em grupo. }\end{array}$ & $\begin{array}{l}\text { Durante as consultas de pré-natal e } \\
\text { puericultura. Outro espaço oportuno é o grupo } \\
\text { de gestantes. }\end{array}$ \\
\hline 2 & Enfermeiro. & $\begin{array}{l}\text { O vínculo formado entre profissional, } \\
\text { gestante, companheiro e família, para } \\
\text { que suas ações sejam verdadeiramente } \\
\text { significativas. }\end{array}$ & $\begin{array}{l}\text { No alojamento conjunto. Aponta que deveria } \\
\text { ser desde o começo do pré-natal. }\end{array}$ \\
\hline 3 & $\begin{array}{l}\text { Médicos, técnicos em } \\
\text { enfermagem, enfermeiros e ACS } \\
\text { que participaram de cursos e/ou } \\
\text { capacitações. }\end{array}$ & Demonstração prática. & $\begin{array}{l}\text { Durante o pré-natal, além de na maternidade e } \\
\text { no pós-parto hospitalar e domiciliar. }\end{array}$ \\
\hline 4 & $\begin{array}{l}\text { Profissionais de saúde com o } \\
\text { médico como protagonista. }\end{array}$ & $\begin{array}{l}\text { Campanhas de incentivo a } \\
\text { amamentação. }\end{array}$ & Sem informação \\
\hline 5 & $\begin{array}{l}\text { Dos profissionais que passaram } \\
\text { informações sobre aleitamento } \\
\text { para as mães, } 35,90 \% \text { foram } \\
\text { médicos, 23,08\% enfermeiros, } \\
25,64 \% \text { não pode responder, } \\
10,26 \% \text { médico e enfermeiro e } \\
2,56 \% \text { com agente de saúde ou } \\
\text { com estudantes de medicina. }\end{array}$ & $\begin{array}{l}\text { Criação de grupo operativo em } \\
\text { educação em saúde para gestantes e } \\
\text { puérpera. }\end{array}$ & $\begin{array}{l}\text { O local em que receberam as informações foi: } \\
33,33 \% \text { na UBS, } 23,08 \% \text { nunca receberam } \\
\text { informações, } 17,95 \% \text { na maternidade, } 7,69 \% \\
\text { buscaram conhecer o tema por meio de } \\
\text { pesquisa na internet, } 5,13 \% \text { através de conversa } \\
\text { com amigos e familiares e } 2,56 \% \text { durante } \\
\text { consulta em clínicas particulares. }\end{array}$ \\
\hline 6 & Enfermeiro. & $\begin{array}{l}\text { Meios de comunicação e atividades em } \\
\text { grupo, com rodas de conversas com } \\
\text { consultor de lactação, visita da futura } \\
\text { nutriz ao Banco de Leite Humano da } \\
\text { cidade e contato telefônico após } 48 \\
\text { horas da alta. }\end{array}$ & $\begin{array}{l}72 \% \text { das gestantes relataram que receberam } \\
\text { todas as informações referentes aleitamento } \\
\text { materno desde a primeira consulta do pré-natal. } \\
\text { Porém, aponta que elas deveriam ser } \\
\text { trabalhadas por mais vezes, até o momento do } \\
\text { pós-parto. }\end{array}$ \\
\hline 7 & Enfermeiros. & $\begin{array}{l}\text { Por meio de massagens, ordenha das } \\
\text { mamas e orientações, além da utilização } \\
\text { do genograma para contribuir para a } \\
\text { compreensão da estrutura e contexto } \\
\text { familiar. }\end{array}$ & $\begin{array}{l}\text { Durante o pré-natal algumas famílias deste } \\
\text { estudo vivenciaram a ausência de orientações } \\
\text { adequadas nas UBS e nas maternidades durante } \\
\text { o pré-natal. }\end{array}$ \\
\hline 8 & $\begin{array}{l}\text { A enfermagem, mas } r \\
\text { necessidade da atuação de uma } \\
\text { equipe multiprofissional } \\
\text { evidente. }\end{array}$ & Uma assistência de forma não verbal. & $\begin{array}{l}\text { 46,4\% das mulheres participantes revelou } \\
\text { receber orientação sobre a amamentação apenas } \\
\text { no ambiente hospitalar após o nascimento do } \\
\text { RN. Durante a gestação, um número de mães } \\
\text { considerável não recebeu as orientações de } \\
\text { forma adequada. }\end{array}$ \\
\hline 9 & Enfermeiro. & $\begin{array}{l}\text { Plano de ações contendo dinâmicas, } \\
\text { palestras, visitas domiciliares e criação } \\
\text { de grupos de gestante. Devem ser } \\
\text { indicadas leituras e materiais educativos } \\
\text { alusivos ao aleitamento materno. }\end{array}$ & $\begin{array}{l}\text { A gestante deve ser incentivada desde a } \\
\text { primeira consulta pré-natal à amamentação. }\end{array}$ \\
\hline 10 & $\begin{array}{l}\text { Enfermeiro e médico. } \\
\text { Com ações reforçadas pelos } \\
\text { Agentes Comunitários de Saúde e }\end{array}$ & $\begin{array}{l}\text { Orientações individuais nas consultas e } \\
\text { palestras para grupos de gestantes. Tais } \\
\text { ações complementadas com visitas }\end{array}$ & $\begin{array}{l}\text { Ações pontuais em algum momento específico } \\
\text { do pré-natal, puerpério ou puericultura. }\end{array}$ \\
\hline
\end{tabular}




\begin{tabular}{|c|c|c|c|}
\hline & $\begin{array}{l}\text { enfermeiros durante as visitas } \\
\text { domiciliares. }\end{array}$ & $\begin{array}{l}\text { domiciliares e com a participação do } \\
\text { banco de leite humano. }\end{array}$ & \\
\hline 11 & $\begin{array}{l}\text { Predominantemente pelo } \\
\text { enfermeiro }(32,0 \%) \text {. }\end{array}$ & $\begin{array}{l}40,6 \% \text { das mulheres da pesquisa } \\
\text { apontou ausência de qualquer } \\
\text { orientação quanto a amamentação. } \\
\text { Suporte ativo e emocional, e } \\
\text { informações através de ações } \\
\text { educativas. }\end{array}$ & $\begin{array}{l}\text { A maioria das puérperas recebeu informações e } \\
\text { auxílio apenas no ambiente hospitalar, } \\
\text { indicando que não obteve o preparo adequado } \\
\text { para amamentar durante sua gestação. }\end{array}$ \\
\hline 12 & Equipe multiprofissional. & $\begin{array}{l}\text { Grupos de educação em saúde voltados } \\
\text { para as gestantes. }\end{array}$ & $\begin{array}{l}\text { É importante que a mãe seja orientada em } \\
\text { relação ao aleitamento materno desde a } \\
\text { primeira consulta de pré-natal. }\end{array}$ \\
\hline 13 & $\begin{array}{l}\text { Médico e agentes comunitários de } \\
\text { saúde. }\end{array}$ & $\begin{array}{l}\text { Formação de grupos de gestantes } \\
\text { (63,5\% não participaram desses grupos) } \\
\text { e orientações durante visita domiciliar }\end{array}$ & $\begin{array}{l}65,5 \% \text { das mães receberam recomendações } \\
\text { durante a internação. No puerpério, } 64,7 \% \text { das } \\
\text { mães foram visitadas em seu domicílio pela } \\
\text { ESF no pós-natal. }\end{array}$ \\
\hline 14 & Enfermeiro. & $\begin{array}{l}\text { Uso de modelos ou guias práticos de } \\
\text { como conduzir no processo de } \\
\text { amamentação. }\end{array}$ & $\begin{array}{l}\text { No pré-natal, na internação para o parto, e } \\
\text { também no momento da alta, ressaltando o que } \\
\text { foi dito anteriormente. }\end{array}$ \\
\hline 15 & $\begin{array}{l}\text { Equipe multiprofissional de } \\
\text { saúde. }\end{array}$ & $\begin{array}{l}\text { Orientações em grupo e visitas } \\
\text { domiciliares. }\end{array}$ & $\begin{array}{l}\text { Mais de três quartos das mulheres foi orientada } \\
\text { sobre aleitamento materno, tendo } 59,0 \% \\
\text { recebido orientações na consulta, } 39,2 \% \text { em } \\
\text { grupos educativos e } 4,4 \% \text { durante visita } \\
\text { domiciliar. }\end{array}$ \\
\hline 16 & $\begin{array}{l}\text { Toda equipe de saúde envolvida } \\
\text { no pré-natal, parto/ pós parto. } \\
\text { Agentes comunitários de saúde, } \\
\text { enfermeiras/ parteiras, médico. }\end{array}$ & $\begin{array}{l}\text { Visitas domiciliares, grupos de apoio a } \\
\text { mães e linhas telefônicas ("linhas } \\
\text { diretas"). Deve-se fornecer apoio } \\
\text { prático sobre como amamentar. }\end{array}$ & Nos serviços de maternidade. \\
\hline 17 & $\begin{array}{l}\text { Equipe multidisciplinar de saúde: } \\
\text { enfermeiros, médicos, técnicos de } \\
\text { enfermagem e ACS. }\end{array}$ & $\begin{array}{l}\text { Serviços e grupos de apoio com suporte } \\
\text { ativo, inclusive emocional, além de } \\
\text { informações precisas. }\end{array}$ & $\begin{array}{l}\text { Atendimentos individuais de consulta pré-natal } \\
\text { e em visitas domiciliares. }\end{array}$ \\
\hline 18 & $\begin{array}{l}\text { O enfermeiro ou outro } \\
\text { profissional de saúde. }\end{array}$ & Estratégias educativas. & $\begin{array}{l}\text { Estudo constatou que } 63,8 \% \text { das mulheres } \\
\text { analisadas negaram terem sido orientadas } \\
\text { acerca do aleitamento materno durante as } \\
\text { consultas de pré-natal. Considera-se que o pré- } \\
\text { natal é o momento oportuno de iniciar as } \\
\text { orientações. }\end{array}$ \\
\hline 19 & $\begin{array}{l}\text { Equipe multiprofissional de } \\
\text { saúde. }\end{array}$ & $\begin{array}{l}\text { Por meio de atividades teóricas e } \\
\text { práticas, leitura e discussão de textos, } \\
\text { troca de experiências, dinâmicas de } \\
\text { grupos. }\end{array}$ & Nas consultas da Rede de Atenção Básica. \\
\hline 20 & Equipe multidisciplinar. & $\begin{array}{l}\text { Formação de grupos de apoio à gestante } \\
\text { com a participação dos familiares e } \\
\text { visitas domiciliares }\end{array}$ & $\begin{array}{l}\text { No acompanhamento pré-natal. Além disso, na } \\
\text { maternidade e no período pós-parto. }\end{array}$ \\
\hline 21 & Equipe de enfermagem. & $\begin{array}{l}\text { Uso de folhetos, cartões-postais, } \\
\text { livretos, filmagem, software educativo, } \\
\text { teorias e modelos de cuidado. }\end{array}$ & $\begin{array}{l}\text { Desde o pré-natal até o puerpério com suporte } \\
\text { adequado principalmente no início da } \\
\text { amamentação. }\end{array}$ \\
\hline
\end{tabular}

Fonte: Autores (2021).

É possível identificar que em relação aos profissionais envolvidos na educação para o aleitamento materno: onze (52\%) artigos indicaram a equipe multidisciplinar da Estratégia Saúde da Família, incluindo o médico, o enfermeiro, o técnico de enfermagem e os agentes comunitários de saúde; outros nove (43\%) artigos apontaram o enfermeiro como principal profissional responsável pelas orientações; e somente um (5\%) estudo apontou o médico como o protagonista. Vale destacar que um artigo aponta estudantes de medicina como parte dos responsáveis pelas orientações.

A análise dos artigos visando identificar os locais e momentos em que as mulheres são orientadas demonstrou os seguintes resultados: dez artigos apontaram as consultas de pré-natal nas Unidades Básicas de Saúde (UBS) como momento e lugar escolhido para as orientações, sendo que quatro desses indicaram ser oportuno abordar o tema já desde a primeira consulta do pré-natal. Outros nove artigos evidenciaram que o suporte é fornecido na maternidade e pós alta hospitalar. Quatro estudos apontaram também a importância das visitas domiciliares como ocasião para orientar e dois mencionaram os grupos de gestantes. 
$\mathrm{O}$ artigo A8, uma pesquisa descritiva, de revisão de literatura, do tipo integrativa demonstrou que um número considerável de mulheres recebe orientações apenas no ambiente hospitalar, não sendo adequadamente orientadas durante a gestação, e quando são, não é suficiente para atender suas demandas.

Em relação as práticas educativas utilizadas, verifica-se uma variedade de práticas, onde os grupos de gestantes mostram-se a estratégia mais relevante citado em doze dos artigos analisados.

Além disso, práticas como oficinas, palestras educativas, vídeos e dinâmicas em grupos foram mencionados em seis estudos. Orientações no domicílio, material educativo (cartilhas, folhetos) e o uso de tele monitoramento também foram mencionados, respectivamente, em cinco, três e dois artigos.

\section{Discussão}

Ao contrário do que ocorre com o restante dos mamíferos, o processo de aleitamento materno humano não é uma ação instintiva. Sendo assim, para que ocorra o sucesso dessa prática entre o binômio mãe-filho, há a necessidade da lactante aprender amamentar, e do lactente ser amamentado. Antigamente, esse ensinamento ocorria através da experiência das mulheres na família, ocorrendo hoje, em grande parte, por meio da equipe multiprofissional da Atenção Primária à Saúde. (Santos, 2017).

\section{Os profissionais de saúde e o ato de amamentar}

Uma das principais ações dos profissionais da Saúde que atuam durante o pré-natal, parto e puerpério, são ações de incentivo, orientação e suporte ao aleitamento materno exclusivo até os 6 meses, dada a importância da amamentação já na primeira hora de vida do recém-nascido, que atua como fator protetor contra a mortalidade neonatal. (Antunes et al., 2017).

Estas ações são realizadas pelas equipes multiprofissionais: médicos, técnicos de enfermagem, enfermeiros, agentes comunitários de saúde (ACS) e fonoaudiólogos, apresentando cada qual, seu papel distinto nesse momento. (Antunes et al. 2017).

Contudo, nem sempre a equipe multiprofissional possui conhecimento sobre amamentação, sendo que poucos profissionais realizam cursos específicos na área de saúde da mulher e da criança, para aperfeiçoar sua abordagem, contribuindo assim para as taxas de amamentação permanecerem estagnadas. (Antunes et al., 2017). A maioria dos profissionais apenas aprenderam sobre o tema durante sua formação e alguns deles, como os auxiliares e técnicos de enfermagem e os agentes comunitários, nem nesses períodos. (Siqueira et al., 2017).

Estas informações mostram a necessidade de investir no aprimoramento técnico-científico de toda a equipe multiprofissional, pois a falta de qualificação gera um obstáculo para o sucesso do processo do aleitamento exclusivo. Cabe destacar, que além do desejo da amamentar, a lactante necessita saber os benefícios do AM, aprender a técnica da pega e ter apoio dos profissionais, da comunidade e da família. Bem como, os serviços de saúde devem desenvolver ações que priorizem o AME, como os dez passos para promover a amamentação da Iniciativa Hospital Amigo da Criança, sendo isto somente possível, estando a equipe devidamente habilitada técnica e cientificamente, para auxiliar a lactante. (Antunes et al., 2017).

Algumas informações que são essenciais para todo profissional da saúde que auxilie lactantes ainda são pouco abordadas nas formações, sendo elas: ordenha, dieta da nutriz, planejamento familiar, falácia do leite fraco, componentes do leite materno, medicações contraindicadas no aleitamento, mitos e crenças sobre aleitamento, questões psicológicas envolvidas no aleitamento materno, ergonomia para amamentar, como abordar/orientar uma nutriz, conservação e doação de leite materno, contraindicações para a amamentação e desmame. (Siqueira et al., 2017). 
Com isso, foi possível constatar que a equipe multiprofissional está mais direcionada nos aspectos técnicos e biológicos da amamentação, esquecendo-se das outras dimensões integradas nesse processo, tais como as fisiológicas, psicológicas, socioculturais e políticas, as quais tem grande impacto na manutenção da lactação. (Siqueira et al., 2017).

Algumas políticas públicas estão sendo realizadas a fim de auxiliar na capacitação do profissional da saúde, principalmente do médico. Nó crítico 1 (Bebê sadio mama no peito) e 2 (Peito amigo) são exemplos de projetos de intervenções que podem ser realizadas para diminuir essa defasagem de conhecimento e técnica da equipe multiprofissional. (Silva et al., 2019).

A nó crítico 1, apresenta como atores sociais: médicos e enfermeiros, atuando como coordenadores dos grupos operativos; técnicos de enfermagem realizando as pesagens e aferições da pressão das gestantes; ACS, realizando uma busca ativa e convidando as gestantes e puérperas para essa ação. Já a nó crítico 2, têm como responsabilidades: as médicas e enfermeiras realizando palestras no grupo de gestantes; ACS incentivando as gestantes a procurem os grupos. (Silva et al., 2019).

Esses dois exemplos de ações apresentam como objetivo ampliar o conhecimento dos profissionais e das lactantes sobre a importância do aleitamento materno e assim, aumentar a quantidade de mães que amamentam seus filhos, bem como aumentar as demandas em grupos de gestantes, respectivamente. Assim, observa-se alguns tipos de estratégias de incentivo ao aleitamento materno, que podem ser realizadas para uma melhor capacitação profissional e também a adesão das gestantes ao AME. (Santos, 2017).

\section{Os espaços educativos}

Quando analisado o momento ideal para a realização das orientações, nota-se que um pré-natal qualificado e com ações preventivas são essenciais para garantir que as lactantes se tornem aptas e seguras para o processo da amamentação. Contudo, foi observado que somente $60 \%$ das gestantes atendidas pelo SUS recebem todas as orientações recomendadas durante o pré-natal. (Alves et al., 2018).

Sendo assim, para sanar esse déficit, e ter um pré-natal de baixo risco e de qualidade, foi escolhido a Atenção Primária à Saúde como o local ideal para ocorrer essas orientações, durante as consultas do pré-natal, onde o ideal é que esse acompanhamento ocorra entre sete consultas ou mais, iniciando antes das 12 primeiras semanas de gestação, criando o vínculo da gestante com a maternidade. A periodicidade e o vínculo garantem diminuição de agravos e complicações, e favorece que gestantes tenham acesso na hora do parto ou em emergências, diminuindo a mortalidade materna e neonatal. (Alves et al., 2018).

Além disso, outra variável que pode ser destacada como influenciadora na aderência das orientações do pré-natal, é se a gestante é primípara, pois estas não têm experiência positivas ou negativas sobre a amamentação. Desta forma, as orientações recebidas durante o pré-natal são fortemente propulsoras no desejo de amamentar. (Silva et al., 2018).

Outros períodos destacados para que possam ocorrer as orientações sobre o aleitamento materno, são em grupos educativos, na maternidade e no momento da visita domiciliar. Todas essas informações ganham relevância, quando constatado que gestantes que tiveram menos de seis consultas pré-natais, com parto em hospitais, sem a iniciativa do hospital amigo da criança, e sem amamentar durante a alta hospitalar, obtiveram uma baixa prevalência de AME. (Alves et al., 2018).

De acordo com Silva et al. (2018), o momento mais oportuno para as gestantes, para iniciar as orientações sobre o aleitamento, é o puerpério imediato, pois as consultas de pré-natal têm como finalidade, realizar os procedimentos de rotina, como avaliar o curso da gestação. Durante o puerpério, a mãe está junto ao recém-nascido, podendo-se então, observar como ocorre a amamentação, e assim auxiliando-a. Foi observado que um grande número de profissionais da saúde está optando por 
realizar uma orientação superficial sobre a amamentação durante o pré-natal, privilegiando o momento da consulta puerperal para auxílio das informações.

\section{As estratégias educativas}

De acordo com Pereira et al. (2010), dentre essas estratégias realizadas no processo educativo, as orientações em grupo devem ser utilizadas, pois são associadas a prevalências mais elevadas de aleitamento materno exclusivo e apresentamse como fontes importantes de apoio à amamentação.

Mães que participam de grupos se sentem mais assistidas devido a diversidade de experiências compartilhadas e segurança que este espaço proporciona, trazendo contribuições como a diminuição da ansiedade e compreensão dos sentimentos que surgem nesse período. De maneira geral, a atividade grupal apresenta o intuito de complementar o atendimento das consultas, contribuindo para o oferecimento de um suporte humanizada, que permite a aderência à hábitos considerados mais adequados e a aproximação entre profissionais e gestantes. (Frigo et al., 2012).

Contudo, a informação, muitas vezes, não é o bastante para que as mulheres tenham motivação e sucesso no processo do aleitamento materno, pois a informação acaba sendo cognitiva e não implica necessariamente em acessar as vias afetivas ou do desejo. É preciso acionar outras vias além da orientação prescritiva, sendo por isso propostas dinâmicas de grupo, com uso de recursos como brincadeiras, atividades e vídeos que visem a troca de experiências e a soma de conhecimentos. (Bezarra et al., 2020).

Recomenda-se que o trabalho grupal aconteça uma vez por mês, sendo discutindo temas sugeridos pelas próprias participantes e liderados por profissionais capacitados a informar e esclarecer possíveis dúvidas, considerando sempre as experiências, valores, medos, anseios, expectativas e, principalmente, a rede de apoio familiar das mulheres. Sugere-se também, a entrega de leituras e materiais complementares, como cartilhas e folhetos, contendo dicas e orientações não só para as gestantes, mas para seus companheiros e familiares. (Frigo et al., 2012).

Dentre os temas que devem ser trabalhados com as mães, pode-se citar: o tempo ideal de aleitamento materno exclusivo e aleitamento materno complementado, as vantagens da amamentação para o lactente, as consequências do desmame precoce, a importância da amamentação ainda na sala de parto, manutenção da lactação e produção do leite, técnica adequada envolvendo local, posição e pega.

Além disso, faz necessário que as mulheres saibam dos problemas e inconvenientes que podem ocorrer, como identificá-los e preveni-los: demora na descida do leite, má sucção do bebê, mamilos invertidos ou planos, ingurgitamento mamário, fissuras mamilares, mastites seja por ingurgitamento ou processo infeccioso dentre outras que constituem juntamente com as crenças e mitos acerca do aleitamento as maiores causas do desmame precoce.

Com o distanciamento social ocasionado pelo advento do novo Coronavírus (Covid-19), os grupos de gestantes tiveram de ser suspensos, perdendo-se um espaço fundamental de orientação. Em um panorama de incertezas e inseguranças de um grave problema de saúde mundial, as lactantes tornam-se mais sujeitas à alterações emocionais e preocupações, destacando-se ainda mais a importância de um suporte adequado e contínuo. (Cabral et al., 2020).

Dessa forma, estratégias de acompanhamento à distância precisaram ser reforçadas e implementadas, como tele monitoramento e ações educativas nas mídias sociais com a criação de grupos virtuais voltados para a interação com gestantes. A iniciativa mostra-se prática, viável, de baixo custo e com um promissor potencial de impulsionar a duração da amamentação exclusiva. (Cabral et al., 2020).

O grupo virtual Projeto Amamenta Mamãe demonstrou que a prática online impactou positivamente na duração e frequência do aleitamento materno exclusivo entre as mulheres participantes. O estudo acompanhou 123 mulheres após a alta 
hospitalar que participavam de um grupo fechado de rede social online, onde semanalmente eram publicados cartazes sobre temas relacionados à amamentação e era estabelecida uma comunicação ativa com as mães. (Cavalcanti et al, 2019).

A formação dos grupos tem como objetivo não ser apenas uma fonte unidirecional de informação, mas fortalecer o diálogo e a participação das mulheres, permitindo a construção de relações, a troca de saberes e a identificação mútua de experiências e aprendizados. O gerenciamento dos grupos virtuais por profissionais do hospital em que as mulheres realizaram o parto ou da unidade de saúde em que fizeram o acompanhamento pré-natal garante confiabilidade das usuárias em relação às informações compartilhadas virtualmente. (Lima et al., 2020).

Essa segurança e a ampliação das relações interpessoais são apontadas como umas das principais contribuições desses grupos. Além disso, a possibilidade da utilização de vídeo-chamadas é uma interessante forma de prestar auxílio, sendo possível visualizar a dinâmica da amamentação, bem como buscar maior vínculo e proximidade. (Cabral et al., 2020). Outra estratégia que a internet proporciona, é a realização de lives (encontros online em tempo real) com profissionais da área materno-infantil, como pediatras, obstetras, nutricionistas, psicólogos e fisioterapeutas, para fornecer informações com embasamento cientifico e de qualidade. (Lima et al,, 2020).

Uma tecnologia que também vem ganhando destaque como dispositivo agregador na atenção à saúde das lactantes é o suporte por telefone, que tem se mostrado como uma ferramenta útil e acessível de promoção e apoio à amamentação. Sugerese que a ligação ocorra no puerpério imediato, como forma de ajudar com o início da prática, superando as possíveis dificuldades iniciais e tornando as mães confiante para manter o aleitamento.

É importante ressaltar que não se trata de uma intervenção "pronta" e "concreta", mas que se constrói no momento do contato e diálogo entre profissional e participantes, desse modo, o domínio e experiência do profissional sobre o assunto trabalhado é fundamental para o sucesso da intervenção e para a eficácia sobre os desfechos desejados, sendo promissor o treinamento e a capacitação dos profissionais responsáveis. (Oriá et al., 2018).

\section{Conclusão}

Com a realização deste estudo, foi possível observar que as estratégias e ações realizadas pela equipe multidisciplinar no incentivo ao aleitamento materno, desde o acompanhamento durante a gestação no pré-natal até o momento na maternidade e pós-parto são de extrema importância para o êxito da amamentação. É relevante ressaltar que no conhecimento dos profissionais de saúde ainda existem lacunas que precisam ser preenchidas para melhorar a capacitação da equipe na temática, bem como a realização de orientações durante o atendimento à gestante e puérpera.

Nota-se que é essencial a presença da atuação dos profissionais desde a primeira consulta pré-natal e durante o parto imediato e alta hospitalar, oferecendo todo apoio e orientações necessárias com empatia e serviço qualificado.

É imprescindível também, a efetivação de ações educativas diversas, especialmente a formação dos grupos de gestantes, presenciais ou online que promovam a amamentação, e demais orientações que permeiam esse processo, considerando a mulher em seus aspectos biopsicossociais e espirituais. Nesse sentido, uso de tele monitoramento, tendo em vista a era digital em que vivemos e o cenário em meio a pandemia, fortalecendo a rede de atenção mãe/bebê e minimizando o desmame precoce.

Ademais, essa pesquisa restringe-se a estudos no âmbito da APS, não podendo ser generalizado a mulheres que são atendidas por médicos particulares ou de convênios durante o pré-natal e puerpério, as quais de forma geral não recebem acompanhamento multiprofissional, grupal e nem em seu domicilio, ficando restrita a consultas em consultório. Sendo necessários mais estudos nesse cenário a fim de identificar como se dá tal fenômeno.

Ainda, deve-se incluir o pai e demais membros da família e rede de apoio da gestante e lactante nas orientações, visto que a postura dos mesmos impacta diretamente na decisão e período de amamentação. Estes devem ser envolvidos nas 
orientações desde o pré-natal, e permanecer durante o puerpério. Bem como, tais orientações, devem ser realizadas de forma massificada a fim de romper com mitos e tabus sociais que envolvem a amamentação materna, a fim de que a comunidade, empresas e demais órgãos tornem-se incentivadores da amamentação.

Recomenda-se que pesquisas futuras sejam conduzidas sobre o tema, a fim de que se conheça melhor como vêm sendo prestadas as orientações em aleitamento materno na atenção primária, principalmente em relação a assistência online no período pós pandemia.

\section{Referências}

Aleixo T. C. S., Carleto E. C., Pires F. C., \& Nascimento J. S. G. (2019). Conhecimento e análise do processo de orientação de puérperas acerca da amamentação. Rev. Enferm, (9)59:1-18. 10.5902/2179769236423

Alves J. S., Oliveira M. I. C., \& Rito R. V. V. F. (2018). Orientações sobre amamentação na atenção básica de saúde e associação com o aleitamento materno exclusivo. Ciência \& Saúde Coletiva, 23(4):1077-1088. 10.1590/1413-81232018234.10752016

Antunes M. B., Demitto M. O., Soares L. G., Radovanovic C. A. T., Higarashi I. H., Ichisato S. M. T., \& Pelloso, S. M. (2017). Amamentação na primeira hora de vida: conhecimento e prática da equipe multiprofissional. Av.enferm, 35(1):19-2910.15446/av.enferm.v35n1.43682

Bezerra A. E. M., Batista L. H. C., \& Santos R. G. A. (2020). Amamentação: o que pensam as mulheres participantes de um grupo de pré-natal? Rev Bras Enferm, 73(3):e20180338. http://dx.doi.org/10.1590/0034-7167-2018-0338

Brasil. Ministério da Saúde. (2009). II Pesquisa de Prevalência de Aleitamento Materno nas Capitais Brasileiras e Distrito Federal. Brasília/DF: MDS. https://bvsms.saude.gov.br/bvs/publicacoes/pesquisa_prevalencia_aleitamento_materno.pdf

Brasil. Ministério da Saúde. (2015). Estratégia Nacional para Promoção do Aleitamento Materno e Alimentação Complementar Saudável no Sistema Único de Saúde: manual de implementação. Brasília/DF:MDS. https://bvsms.saude.gov.br/bvs/publicacoes/estrategia_nacional_promocao_aleitamento_materno.pdf

Cabral C. S., Cavalcanti D. S., Barbosa J. M., Vasconcelos A. C. C. P., Faustino W. M., \& Vianna R. P. T. (2020) Análise de uma estratégia educativa virtual voltada para o apoio ao aleitamento materno exclusivo. Demetra, 15:e45674. https://doi.org/10.12957/demetra.2020.45674

Cabral C. S., Cavalcanti D. S., Barbosa J. M., Vasconcelos A. C. C. P., \& Vianna R. P. T. (2020). Inserção de um grupo virtual na rede social de apoio ao aleitamento materno exclusivo de mulheres após a alta hospitalar. Interface (Botucatu), 24: e190688. https://doi.org/10.1590/Interface.190688

Cavalcanti D. S., Cabral C. S., Vianna R. P. T., \& Osório M. M. (2019). Online participatory intervention to promote and support exclusive breastfeeding: Randomized clinical trial. Matern Child Nutr, 15:e12806. doi:10.1111/mcn.12806

Frigo L. F., Silva R. M., Mattos K. M., Manfio F., \& Boeira G. S. (2012) A importância dos grupos de gestante na atenção primária: um relato de experiência. Rev Epidemiol Control Infect, 2(3):113-114. https://online.unisc.br/seer/index.php/epidemiologia/article/viewFile/2745/2195

Lima A. C. M. A. C. C., Chaves A. F. L., Oliveira M. G., Lima S. A. F. C. C., Machado M. M. T. M., \& Oriá M. O. B. (2020). Consultoria em amamentação durante a pandemia COVID-19: relato de experiência. Esc Anna Nery, 24(spe):e20200350. https://doi.org/10.1590/2177-9465-EAN-2020-0350

Oriá M. O. B., Dodou H. D., Chaves A. F. L., Santos L. M. D. A., Ximenes L. B., \& Vasconcelos C. T. M. (2018). Eficácia de intervenções educativas realizadas por telefone para promoção do aleitamento materno: revisão sistemática da literatura. Rev Esc Enferm USP, 52:e03333. https://doi.org/10.1590/S1980-220X2017024303333

Paiva M. R. F., Parente J. R. F., Brandão I. R., \& Queiroz A. H. B. (2016). Metodologias ativas de ensino-aprendizagem: revisão integrativa. SANARE, Sobral. 15(2):145-153. Recuperado de: https://sanare.emnuvens.com.br/sanare/article/view/1049

Pereira R. S. V., Oliveira M. I. C., Andrade C. L. T., \& Brito A. S. (2010). Fatores associados ao aleitamento materno exclusivo: o papel do cuidado na atenção básica. Cad. Saúde Pública, Rio de Janeiro, 26(12):2343-2354. https://doi.org/10.1590/S0102-311X2010001200013

Ramos A. E., Ramos C. V., Santos M. M., Almeida C. A. P. L., \& Martins M.C.C. (2018). Conhecimento sobre aleitamento materno e alimentação complementar dos profissionais de saúde. Rev Bras Enferm [Internet], 71(6):2953-60. https://doi.org/10.1590/0034-7167-2017-0494

Santos K. V. (2017). Atuação do médico da equipe de saúde da família na orientação da amamentação exclusiva. UFMG. https://www.nescon.medicina.ufmg.br/biblioteca/registro/referencia/0000007260

Silva D. D., Schmitt I. M., Costa R., Zampieri M. F. M., Bohn I. E., \& Lima M. M. (2018). Promoção do aleitamento materno no pré-natal: discurso das gestantes e dos profissionais de saúde. Reme, 22:e-1103. http://www.dx.doi.org/10.5935/1415-2762.20180031.

Silva N. M., Waterkemper R., Silva E. F., Cordova F. P., \& Bonilha A. L. L. (2014). Conhecimento de puérperas sobre amamentação exclusiva. Rev Bras Enferm, 67(2): 290-5. https://doi.org/10.5935/0034-7167.20140039

Silva R. M. M., França A. F. O., Toninato A. P. C., Ferrari R. A. P., Caldeira S, \& Zilly, A. (2019). Promoção do aleitamento materno: práticas de médicos e enfermeiros da atenção primária à saúde. Revista de Enfermagem do Centro-Oeste Mineiro, 9:e3335. https://doi.org/10.19175/recom.v9i0.3335

Siqueira F. P. C., Zutin T. L. M, Kuabara C. T. M., \& Martins T. A. (2017). A capacitação dos profissionais de saúde que atuam na área do aleitamento materno. Investig. Enferm. Imagen Desarr, 19(1): 171-186. 10.1590/1413-81232017221.17292015 
Research, Society and Development, v. 10, n. 12, e500101220871, 2021

(CC BY 4.0) | ISSN 2525-3409 | DOI: http://dx.doi.org/10.33448/rsd-v10i12.20871

Souza M. T., Silva M. D., \& Carvalho R. (2010). Revisão integrativa: o que é e como fazer. Einstein, 8(1):102-6. 10.1590/s1679-45082010rw1134

Visintin A. B., Primo C. C., Amorim M. H. C., \& Leite F. M. C. (2015). Avaliação do conhecimento de puérperas acerca da amamentação. Enferm. Foco, 6 (1/4): 12-16. http://revista.cofen.gov.br/index.php/enfermagem/article/view/570 